\title{
Daily cigarette consumption in early adulthood: age of smoking initiation and duration of smoking $\dagger$
}

\author{
Naomi Breslau \\ Departments of Biostatistics and Research Epidemiology and Psychiatry. Henry Ford Hospital, Detroit. MI and University of \\ Michigan School of Medicine, Ann Arbor, MI, (USA)
}

(Accepted May 6, 1993)

\begin{abstract}
This study considers the extent to which daily consumption of cigarettes in young adults varies by age at first cigarette and duration of smoking. Data come from a random sample of 21- to 30-year-old members of a large HMO in the Detroit area. Daily cigarette consumption by current smokers varied by duration of daily smoking: the longer the duration, the higher the number of cigarettes smoked. Duration from first cigarette to daily smoking bore no relationship to cigarette consumption. When dura tion of daily smoking was statistically controlled, the association between cigarette consumption and age at first cigarette was not statistically significant. The findings suggest that public health efforts to delay daily smoking among adolescents might reduce cigarette consumption in early adulthood.
\end{abstract}

Key words: cigarette consumption; smoking duration; age at first cigarette

\section{Introduction}

Little information is available on the consequences of early smoking initiation for smoking behaviors in adulthood. A recent brief report found an inverse association between the age at which smoking began and the number of daily cigarettes smoked in adulthood (Taioli and Wynder, 1991). The study did not examine the extent to which the increased daily use of cigarettes associated with early initiation was due to the longer duration of smoking in those who had smoked since an early age. National data on number of cigarettes smoked daily in 1970 ,

Correspondence to: Naomi Breslau, Dept. of Psychiatry, Henry Ford Hospital, 2799 West Grand Boulevard, CFP-3, Detroit, MI 48202, USA.

This research was supported by a grant from Kingswood Hospital, Ferndale, MI, a research grant (MH48802) and a Research Scientist Development Award (KO2 MH-00380) from the National Institute of Mental Health, Bethesda, $\mathrm{MD} \dagger$.
1975 , and 1980 show that the average daily consumption increased with age for 21- to 54-yearold current and former smokers (USDHHS, 1984). The association between daily consumption and age was evident in all three survey periods, suggesting that the pattern is not entirely due to differences across cohorts, and might in part reflect an effect of duration of smoking (attendant on increased age) on daily consumption of cigarettes (USDHHS, 1984). Specifying the relative contributions of age of initiation and duration of smoking to consumption levels in adulthood might suggest potential mechanisms underlying variations in level of cigarette consumption.

A recent study reported that the prevalence of regular smoking and heavy smoking among high school students increased with increasing years since smoking initiation (Escobedo et al., 1993). While the study also found that smoking initiation before age 13 was associated with increased odds for regular and heavy smoking, the relative 
importance of age at initiation and duration of smoking was not examined.

In this report, the extent to which daily consumption of cigarettes among young adults varies by age at first cigarette and duration of smoking is examined. Data come from an epidemiologic study of young adults in the Detroit metropolitan area, in which information was elicited on current smoking, age at first cigarette and other aspects of smoking history.

\section{Methods}

A sample of 1200 was randomly selected from all 21- to 30-year-old members of a 400000 member HMO in the Detroit metropolitan area. Personal interviews were conducted in 1989 and telephone interviews were conducted in 1990 , covering events that occurred during the interval. Participation rate in the initial study was $84 \%$ and follow-up completion rate was $99.1 \%$. (One respondent died, another returned to his European country of origin. Of the remainder target sample, ten refused to participate.) The analysis presented herein was performed on data gathered in the follow-up study. The sample was $62 \%$ female, $81 \%$ white, and $29 \%$ college educated; median age in 1990 was 27 years. Detailed information on the population and the sample appears elsewhere (Breslau et al., 1991). In the follow-up interview, information on number of cigarettes smoked daily was gathered from all respondents who have smoked daily for 1 month or more during the follow-up interval. Additionally, respondents were asked about the age at which they smoked their first cigarette (smoking initiation) and the age at which they began smoking daily.

\section{Statistical analysis}

The associations of daily consumption of cigarettes with age of smoking initiation and duration of smoking were examined in multiple regression analyses, with sex and race as covariates. Three hierarchical regressions were calculated. The first regression estimated the relationship between number of daily cigarettes and age at first cigarette, with sex and race as covariates. The second introduced to the model the duration of daily smoking, measured by number of years since daily smoking began, and the third added to the model the duration of experimental smoking, measured by number of years from first cigarette to onset of daily smoking.

A diagnostic procedure was applied to assess the degree to which collinearity in the data matrix potentially degrades the regressions' estimates (Belsley et al., 1980). Neither the first nor the second regression models were found to be threatened by decreased precision of the estimates due to collinearity. Results from the third regression model, which introduced the second duration variable, might be imprecise due to borderline collinearity, with the estimated coefficient of age at first cigarette potentially adversely affected. However, because the addition of the second duration variable in the third regression added an insignificant increment to explained variance in the dependent variable (as will be summarized below), the estimates calculated in the third regression are of little interest. Estimates of the associations of cigarette consumption with age of first cigarette and duration of daily smoking are based on the results of the second regression. Standard regression diagnostics performed on this model failed to detect deviations from the assumptions of linear regression models.

\section{Results}

Of the total 995 young adults from whom follow-up interviews were obtained, $290(29 \%)$ were current smokers (i.e. smoked daily for 1 month during the follow-up interval from 1989 to 1990). The mean age of smoking initiation, i.e. age at first cigarette, in the 290 smokers was 14.8 ( \pm 3.0 ). Duration of daily smoking, i.e. number of years since daily smoking began, was $9.9( \pm 3.9)$ and of experimental smoking, i.e. number of years from first cigarette to onset of daily smoking, was $2.8( \pm 2.7)$. Duration of experimental smoking was inversely related to age at first cigarette, with those who initiated 
Table I. Daily number of cigarettes in current smokers by age at first cigarette.

\begin{tabular}{lrrr}
\hline $\begin{array}{l}\text { Age at 1st cigar- } \\
\text { ette }\end{array}$ & $(N)$ & Mean & $($ S.D. $)$ \\
\hline$<14$ & $(136)$ & 21.0 & $(10.2)$ \\
$15-16$ & $(83)$ & 19.0 & $(9.6)$ \\
$17-20$ & $(58)$ & 16.6 & $(9.2)$ \\
$21 \perp$ & $(13)$ & 13.3 & $(8.7)$ \\
\hline
\end{tabular}

smoking before age 14 taking the longest time to become daily smokers (Breslau et al., 1993).

The bivariate relationship between number of cigarettes smoked daily and age at first cigarette in current smokers is displayed in Table $\mathrm{I}$. A comparison of means of daily cigarette consumption across age of smoking initiation categories reveals a downward gradient, with those in the youngest initiation group showing the highest level of current use.

Before presenting the multivariate analysis of cigarette consumption, Table II displays the bivariate regressions of cigarette consumption on the individual variables included in the model. Age at first cigarette had an inverse association with number of cigarettes smoked daily. Number of years from first cigarette to daily smoking had a weak inverse relationship with current

Table II. Bivariate regressions of daily number of cigarettes on age of first cigarette, duration variables, sex and race $(N=290)$.

\begin{tabular}{llll}
\hline & B & (S.E.) & $P$-value \\
\hline $\begin{array}{l}\text { Age first } \\
\text { cigarette } \\
\begin{array}{l}\text { Duration to } \\
\text { daily smoking }\end{array}\end{array}$ & -0.80 & $(0.19)$ & 0.0001 \\
$\begin{array}{l}\text { Duration of } \\
\text { daily smoking }\end{array}$ & 0.78 & $(0.14)$ & 0.0001 \\
$\begin{array}{l}\text { Sex (Male) } \\
\text { Race (White) }\end{array}$ & 3.78 & $(1.21)$ & 0.002 \\
\hline
\end{tabular}

Unstandardized regression coefficients; standard errors in parentheses.

a Number of years from first cigarette to daily smoking.

${ }^{b}$ Number of years from onset of daily smoking to current age. cigarette consumption (not significant), while number of years of daily smoking had a direct association with current cigarette consumption. Males and whites smoked significantly morc cigarettes than females and blacks. The association between educational achievement and current cigarette consumption (not presented) was not significant $(P=0.132)$.

The results of the hierarchical multiple regressions of number of cigarette smoked daily appear in Table III. Unstandardized partial regression coefficients are presented, with standard errors in parentheses. Controlling for sex and race, age of smoking initiation had an inverse relationship with number of cigarettes smoked daily ( $P=0.001$ ) (Table III, column 1 ). On the average, a 1-year increase in age at first cigarette was associated with a reduction of more than one-half a cigarette. The results also show significant sex and race differences in cigarette consumption. Among daily smokers, males and whites smoked more cigarettes daily than females and blacks, respectively. Firstorder interactions between age of smoking initiation, sex, and race did not improve the fit of the regression model $(P>0.10)$.

Duration of daily smoking, introduced in the second regression, had a positive correlation with number of daily cigarettes, independent of age of smoking initiation $(P=0.0001)$ (Table III, column 2). Each additional year of daily smoking was associated with an increase of 0.63 cigarettes a day, on the average. The addition of duration of daily smoking to the equation markedly reduced the magnitude of the coefficient of age at first cigarette, which was no longer statistically significant. The addition of duration from first cigarette to daily smoking, in the third regression (not presented), did not improve the fit of the model.

In summation the results of this analysis indicate that number of cigarettes smoked daily by the young adults in this sample varied by duration of daily smoking: the longer the duration of daily smoking, the higher the number of cigarettes smoked. Age at first cigarette bore no significant relationship to current cigarette consumption, when duration of daily smoking was 
Table III. Predicting number of cigarettes smoked daily by current smokers: results from hierarchical multiple regressions $(N=290)$.

\begin{tabular}{|c|c|c|c|c|c|c|}
\hline & \multicolumn{3}{|l|}{1} & \multicolumn{3}{|l|}{2} \\
\hline & $\mathrm{B}$ & (S.E.) & $P$ & B & (S.E.) & $P$ \\
\hline Age 1st cigarette & -0.59 & $(0.18)$ & 0.001 & -0.18 & $(0.20)$ & 0.35 \\
\hline Sex (male) & 3.52 & $(1.12)$ & 0.002 & 4.02 & $(1.10)$ & 0.0003 \\
\hline Race (white) & 8.15 & (1.51) & 0.0001 & 7.55 & $(1.47)$ & 0.0001 \\
\hline $\begin{array}{l}\text { Duration of daily } \\
\text { smoking }^{\mathrm{a}}\end{array}$ & & - & & 0.63 & $(0.15)$ & 0.0001 \\
\hline$R^{2}$ & & 0.17 & & & 0.22 & \\
\hline
\end{tabular}

Unstandardized partial regression coefficients; standard errors in parentheses.

${ }^{a}$ Number of years from onset of daily smoking to current age.

taken into account. Further, number of years from first cigarette to onset of daily smoking was unrelated to current cigarette consumption. Estimates from the second regression in Table III (including the estimate of the intercept at 7.94) can be used to illustrate the results. Current cigarette consumption after 10 years of daily smoking would be 23.8 for a white male who smoked his first cigarette at age 12, and 23.1 for a white male who smoked his first cigarette at age 16.

Other results of interest are the associations of number of cigarettes smoked daily with sex and race. Compared with women, men smoked an excess of more than four cigarettes daily, on the average. Compared with blacks, whites smoked an excess of more than seven cigarettes daily, on the average. The excess in the amount of smoking by men vs. women did not differ between blacks and whites.

\section{Discussion}

Inferences from this analysis are confined to the age range of the young adults of the sample. Number of daily cigarettes might not continue to increase beyond a certain time period and might even decrease in older smokers (Kabat and Wynder, 1987; Coambs and Kozlowski, 1992). While limiting the generalizability of the results, the young age of the sample is strategically advantageous for the study of the relationship between daily cigarette consump- tion and duration of smoking or age at first cigarette. In a population of a wider age range, associations among these variables might be obscured by cohort differences in age of smoking initiation and anti-smoking social stance, as well as by age-related changes in individuals' smoking behaviors, such as cessation and reduction of cigarette consumption (Garvey et al., 1983; Coambs and Kozlowski, 1992; Freund et al., 1992)

The results support the distinction between duration of daily smoking and duration of experimental smoking (i.e., from first cigarette to onset of daily smoking) as separate factors in explaining cigarette consumption by young adults. Of the total duration of smoking since the first cigarette, the duration from first cigarette to onset of daily smoking constituted a relatively small fraction. The importance of that period for predicting current cigarette consumption was not supported in the data. In contrast, duration of daily smoking among the young adults in the study was an important factor in daily cigarette consumption. The positive association between duration of daily smoking and level of cigarette consumption is consistent with a physiologic model of dependence, in which continued regular use is associated with increased consumption through the mechanisms of tolerance. The findings suggest that public health efforts to delay the progression to daily smoking among adolescents, if successful, might result in reduced daily cigarette consumption during early adulthood. 


\section{References}

Belsley, D.A., Kuh, E. and Welsch, R.E. (1980) Regression Diagnostics: Identifying Influential Data and Sources of Collinearity, pp.112-115, John Wiley, New York.

Breslau, N., Fenn, N. and Peterson, E.L. (1993) Early smoking initiation and nicotine dependence in a cohort of young adults, Drug Alcohol Depend. 33, 129-137.

Breslau, N., Kilbey, M.M. and Andreski P (1991) Nicotine dependence, major depression, and anxiety in young adults, Arch. Gen. Psychiatry 48, 1069-1074.

Coambs, R.B., Li, S. and Kozlowski, L.T. (1992) Age interacts with heaviness of smoking in predicting success in cessation of smoking, Am. J. Epidemiol. 135, 240-246.

Escobedo, L.G., Marcus, S.E., Holtzman, D. and Giovino, G.A. (1993) Sports participation, age at smoking initiation, and the risk of smoking among US high school students, J. Am. Med. Assoc. 269, 1391 - 1395.
Freund, K.M., D'Agostino, R.B., Belanger, A.J., Kannel, W.B. and Stokes III, J. (1992) Predictors of smoking cessation: the Framingham Study. Am. J. Epidemiol. 135, 957-964.

Garvey, A.J., Bosse, R., Glynn, R.J. and Rosner, B. (1983) Smoking cessation in a prospective study of healthy adult males: effects of age, time period, and amount smoked. Am. J. Public Health 73, 446-450.

Kabat, G.C. and Wynder, E.L. (1987) Determinants of quitting smoking. Am. J. Public Health 77, $1301-1305$.

Taioli, E. and Wynder, E.L. (1991) Effect of the age at which smoking begins on frequency of smoking in adulthood. N. Engl. J. Med. (Letter to the Editor). 325, $968-969$.

USDHHS (1984) The health consequences of smoking: cardiovascular disease. Report of the Surgeon General, Government Printing Office/Washington, DC, Pub. No. (PHS) 84-50204. 